\title{
Antimicrobial Photodynamic Therapy in the Endodontic Treatment of Deciduous Teeth: In Vivo Pilot Study
}

\author{
Maria Luiza da Matta Felisberto Fernandes ${ }^{1}\left({ }^{\circ}\right.$, Caroline Andrade Maia ${ }^{\circledR}$, Alice Machado Carvalho

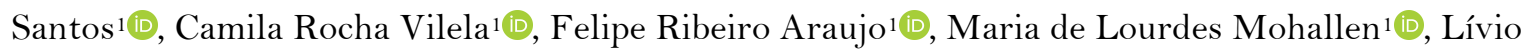 \\ Barros Silveira ${ }^{2} \mathbb{D}$, Alexandre Moreira Fernandes ${ }^{1}[0$
}

${ }^{1}$ Faculty of Dentistry, Newton Paiva University Center, Belo Horizonte, MG, Brazil.

${ }^{2}$ Faculty of Dentistry, Arnaldo Faculty, Belo Horizonte, MG, Brazil.

Author to whom correspondence should be addressed: Dr. Maria Luiza M. F. Fernandes, Av. Silva Lobo, 1718, Nova Granada, Belo Horizonte, MG, Brazil. Phone: +55 31999761406. E-mail: marialuizadamatta@gmail.com.

Academic Editor: Wilton Wilney Nascimento Padilha

Received: 10 October 2019 / Accepted: 29 April 2020 / Published: 18 June 2020

How to cite this article: Fernandes MLMF, Maia CA, Santos AMC, Vilela CR, AraujoFR, Mohallen ML, et al. Antimicrobial photodynamic therapy in the endodontic treatment of deciduous teeth: in vivo pilot study. Pesqui Bras Odontopediatria Clín Integr. 2020; 20:e5309. https://doi.org/10.1590/pboci.2020.111

\begin{abstract}
Objective: To evaluate the Antimicrobial Photodynamic Therapy (aPDT) in infected deciduous teeth by quantifying the viable bacteria in root canal treatment. Material and Methods: Radicular canal cultures were collected $(n=10)$. Four intra-canal samples were collected at four different times in each of the sampled teeth, as follows: Time 1 (T1), baseline: After opening the pulp-chamber; Time 2 (T2): After application of aPDT; Time 3 (T3): After mechanical, chemical manipulation; Time 4 (T4): After a second application of aPDT. The aPDT was performed with a $4 \mathrm{~J} / \mathrm{cm}$ energy low-intensity diode, together with $0.005 \%$ methylene blue as a photosensitizer. The clinical specimens were taken to the laboratory for a bacteria count (colony forming units) and the results were statistically analyzed using the Friedman and Wilcoxon tests, with a significance level of $\alpha=0.05$. Results: Statistical differences were seen between the numbers of bacteria at times T1-T2, T1-T3 and T1-T4 on the cultivated plates. However, no significant statistical differences were observed between the number of bacteria in samples T2-T3, T2-T4 and T3-T4. Conclusion: Antimicrobial photodynamic therapy can be a good co-adjuvant in root canal decontamination of necrotic primary teeth.
\end{abstract}

Keywords: Low-Level Light Therapy; Photochemotherapy; Dental Pulp Necrosis; Tooth, Deciduous. 


\section{Introduction}

Keeping the deciduous dentition until physiological exfoliation occurs is essential, as it ensures adequate eruption of healthy permanent teeth. The main causes of endodontic treatment in deciduous teeth are extensive carious lesions and traumatic lesions. Endodontic treatment of deciduous teeth is difficult due to the varied anatomical and physiological characteristics of root canals [1]. Success in endodontic treatment occurs when there is a reduction in the root canal microbiota. The microbiota is comprised of anaerobic, facultative and aerobic bacteria that are sensitive to chemical-mechanical instrumentation [2,3]. Studies have shown that Enterococcus faecalis, microaerophilic and mesophilic microorganisms are frequently involved in persistent endodontic infections [4-6].

Common difficulties in conventional endodontic treatments include the presence of irregular root resorption; microbial resistance after endodontic treatment; the presence of accessory foramina; lower tolerance to prolonged treatment; movement of the child during access to the canal; lack of cooperation of the child in care; instrumentation and filling. In addition, some studies have found that only the use of mechanical instrumentation and root canal irrigation is insufficient in eliminating bacteria from the infection process. Therefore, it is important to use additional techniques that may offer assistance with antimicrobial activity $[7,8]$. Different studies have concluded that photodynamic therapy can aid in the endodontic treatment of deciduous teeth, resulting in a significant reduction in the number of microbiota present in deciduous teeth with necrotic pulp [1,9].

Photodynamic antimicrobial therapy (aPDT) is based on the concept that a non-toxic dye, known as photosensitizer (FS), can be activated by low doses of visible light and an appropriate wavelength to generate singlet oxygen and free radicals, which are cytotoxic to bacterial cells [10]. Blue dyes, especially toluidine blue and methylene blue, used with a low-intensity laser are effective in eliminating bacteria [11]. Photodynamic therapy has been used in some studies as a support for the elimination of microorganisms, along with the mechanical-chemical preparation of the root canals of deciduous teeth $[1,6,8,9,12]$. The aPDT can then be an auxiliary therapy to reduce the microbiota in the endodontic treatment of deciduous teeth [1,6,9].

Thus, the objective of this study was to conduct an evaluation in vivo of the effect of aPDT therapy on the microbiota present in the root canals of deciduous teeth.

\section{Material and Methods}

Protocol and Sample

The present study followed the same protocol published in the literature for the use of aPDT and microbiological analysis $[1,6,8,9]$. Ten deciduous teeth with necrotic pulp, from children of both genders between ages 3 years and 5 years, with a mean age of 4 years, were treated at the clinic for babies at the Faculty of Dentistry the University Center of Newton Paiva (UCNP), were selected.

The participants represented the total number of children who met the inclusion criteria for the study, representing $76.9 \%$ of the children who were treated at the UCNP dental clinic for babies who required endodontic treatment for pulp necrosis (10 out of 13 children with teeth that had pulp necrosis). This was a sample of convenience. However, it represented the total number of children who met the inclusion criteria for the study. The other clinical cases presented the possibility of major coronary damage from the invasion of the biological space, therefore contradicting the benefits of endodontic treatment. All teeth analyzed were anterior single root teeth. All parents agreed with their child's participation in the research using the aPDT protocol described in the literature $[1,6,8,9]$. 


\section{Inclusion Criteria}

The study included children with carious lesions in deciduous teeth that affected the pulp, diagnosed as necrotic pulp. This was determined by the presence of a radiolucid area in the furcation that was observed by peri-apical radiography. The radiographic diagnosis was performed with periapical radiography on children's radiographic film (Kodak Brasil, São José dos Campos, SP, Brazil), with children positioned by using a parallelism technique in the XRM apparatus $(70 \mathrm{kV} \times 12 \mathrm{~mA}$, Model D700 Max Mobile Speaker, Alliage S/A Indústrias Médico Odontológica, Ribeirão Preto, SP, Brazil). The children were not taking any medications.

\section{Exclusion Criteria}

Exclusion criteria included children who were currently under medical treatment and using antibiotics; children with necrotic pulp in the teeth, with the radiolucent area affecting the dental follicle of the permanent successor element recommended for exodontia; children with deciduous teeth with root resorption of more than half the total length of the root; and any dental condition that contraindicated the endodontic treatment.

\section{Clinical Procedure and Sample Culture}

For convenience, the study was carried out in two stages: 1) A clinical stage, in which 10 clinical specimens were collected from 10 anterior deciduous teeth, and then submitted for microbiological analysis; and 2) A laboratory stage, in which the clinical specimens were processed in the laboratory with a culture and bacteria colony forming units (CFUs) count.

\section{Clinical Stage}

A researcher with experience in pediatric dentistry performed the clinical stage (MLMFF). After infiltrative anesthesia of 2\% lidocaine with Epinephrine 1:100.000 (Aphacaine, DFL Indústria e Comércio S/A, Rio de Janeiro, RJ, Brazil) the tooth was isolated with a rubber dam (Madeitex Indústria e Comércio de Artefatos de Látex Ltda., São José dos Campos, SP, Brazil), the carious tissue and pulp chamber ceiling were removed with a spherical rotary bur no. 2 at high rotation and was cooled with a sterile saline drip. A sterile Kerr n-file, K15, was initially used to check access to root canals. An endodontic locator (Endus, Gnatus Produtos Médicos e Odontológicos Ltda, Barretos, SP, Brazil) was used to establish the apical patency. The limit for mechanical-chemical instrumentation was $1 \mathrm{~mm}$ short of the apical terminus (working length).

The radicular canals of each deciduous tooth received a sterile paper cone with an anatomic diameter compatible with the canal for 30 seconds. The first sample of bacterial contamination was immediately placed in the brain heart infusion (BHI) - baseline step (T1). After, the first aPDT was performed and a second bacterial sample (T2) was collected. Then, the chemical-mechanical instrumentation was performed with Kerr files (Maillefer Brazil S. A., São Paulo, SP, Brazil) and an anatomic diameter compatible to the radicular canal, along with 0.5\% sodium hypochlorite irrigation (Fórmula \& Ação Farmácia, São Paulo, SP, Brazil) and Endo PTC (urea peroxide, Tween- 80 and Carbowax; Fórmula \& Ação Farmácia, São Paulo, SP, Brazil). After this stage, another bacteriological sample (T3) was collected. A second aPDT was then applied and a last microbial sample was collected (T4).

The collection of the clinical specimens for microbiological analysis occurred at four distinct times, termed times $1,2,3$ and 4 . 
- Time 1 (T1): After the root canal path was opened and conferred with the K15 file (Kendo, VDW GmbH, Munich, Germany) and an endodontic locator (Endus, Gnatus Produtos Médicos e Odontológicos Ltda, Barretos, SP, Brazil), a sterile absorbent paper cone compatible with the anatomical diameter of the root canals was introduced for 30 seconds. The contaminated clinical specimen was immediately placed in a tube containing brain heart infusion (BHI) broth medium.

- Time 2 (T2): After the collection of the clinical specimen, the first aPDT therapy was applied by placing a sterile paper cone with an anatomic diameter compatible with the canal and soaked with 0.005\% methylene blue photosensitizer (Chimiolux 5, DMC Importação e Exportação de Equipamentos LTDA, São Carlos, SP, Brazil) in the canals, maintaining the photosensitizing agent for 3 minutes of pre-irradiation time. A red laser light of low intensity, $660 \mathrm{~nm}$ wavelength, was applied for 40 seconds in the canals using the portable Laser Duo MMO apparatus (MM Optics Ltda, São Carlos, SP, Brazil) and energy of $4 \mathrm{~J} / \mathrm{cm}$ by using an intracanal plastic optical fiber (MM Optics Ltda, São Carlos, SP, Brazil). The second clinical specimen was collected with a sterile absorbent paper cone compatible with canal diameters for 30 seconds. This second sample of canals with necrotic pulp of deciduous teeth was immediately transferred to the BHI broth medium.

- Time 3 (T3): After the first application of aPDT therapy, the mechanical-chemical instrumentation was performed with K-files with an anatomical diameter that was compatible with the root canal and with $0.5 \%$ sodium hypochlorite irrigation. After the instrumentation was completed, the root canals received a sterile absorbent paper cone with an anatomical diameter compatible with the canal for 30 seconds to collect the third clinical specimen, which was immediately transferred to a BHI broth tube.

- Time 4 (T4): After the conclusion of the chemical-mechanical instrumentation, a sterile paper cone with an anatomic diameter compatible with the canal and soaked in $0.005 \%$ methylene blue photosensitizer (Chimiolux 5, DMC Importação e Exportação de Equipamentos Ltda., São Carlos, SP, Brazil) was inserted into the canals and kept there for 3 minutes. After the removal of the cone that was soaked with a photosensitizing agent, the red laser was again applied using the Portable Laser Duo (MM Optics Ltda., São Carlos, SP, Brazil) with $4 \mathrm{~J} / \mathrm{cm}^{2}, 100 \mathrm{~mW}$ power output and $660 \mathrm{~nm}$ was applied for 40 seconds, leaving the laser's active tip in contact with the canal. A new collection of the microbiota was performed using the same protocol as above. In brief, sterile absorbent cones compatible with the root canals were introduced for 30 seconds, and the sample was immediately transferred to a tube containing BHI broth. After these steps the teeth were filled with Guedes Pinto paste and restored with resin-modified glass ionomer cement (Vitremer, 3M do Brasil, Sumaré, SP, Brazil).

\section{Laboratory Stage}

A researcher with experience in microbiology performed this laboratory step (MLM). All samples collected at four distinct times of the clinical stage were submitted for culture to visually count the total number of bacteria. All tests were performed in duplicate.

\section{Microbiological Analysis}

Tubes containing BHI broth were inoculated with the collected clinical specimens. The clinical specimens were transported to the microbiology laboratory of the UCNP in a suitably cooled container. The laboratory procedure involves the microdilution technique as follows: $0.5 \mathrm{~mL}$ from the BIH tubes containing 
the clinical specimens was transferred to tubes containing $4.5 \mathrm{~mL}$ of NaCl$/$ peptone $(5 \mathrm{~g} / \mathrm{L} ; 10 \mathrm{~g} / \mathrm{L})$ (HiMedia Laboratories Private Limited, Mumbai, India) $\left(1: 10=10^{-1}\right)$ for each of the collected specimens (T1 to T4).

In brief, $0.5 \mathrm{~mL}$ of dilution 10-1 was transferred to a new tube containing $4.5 \mathrm{~mL}$ of peptone solution to make dilution 10-2, and the procedure was repeated until dilution 10-6. In each step, the dilutions were homogenized for 15 seconds in a shaker. Twenty-five $\mathrm{mL}$ of each dilution was collected with a sterile micropipette, placed onto blood agar plates (Newprov Produtos Para Laboratório, Pinhais, PR, Brazil) and spread on the plate using a sterile glass loop. The blood agar plates were then incubated at $37^{\circ} \mathrm{C}$ for 5 days in a microaerophilic chamber (candle method). All tests were performed in duplicate. After incubation, the colonies obtained were counted and the result expressed in $\mathrm{CFU} / 25 \mathrm{~mL}$.

\section{Statistical Analysis}

The results of blood agar counts were submitted for descriptive and analytical statistics for each of the clinical specimens. The normality of the results was tested using the Ryan-Joiner test, available in the Minitab Software, version 19 (Minitab LLC, State College, PA, USA) similar to the Shapiro-Wilk test. The non-normal distribution of data made it impossible to use parametric statistical tests. Thus, the Friedman test was used, encompassing all the results obtained from the 4 times, and the Wilcoxon-test was used to compare dependent samples, paired, at the different laboratory analysis times. A level of significance of $95 \%(\alpha=0.05)$ was considered statistically significant.

Ethical Considerations

This study was approved by the Ethics Committee on Human Research (CAAE 89703518.4.0000.5097). Informed consent was obtained from the parents of all participant children.

\section{Results}

Ten clinical specimens were collected. After incubation each plate was visually inspected and CFU were counted. Fungal growth on the culture plates was not observed. The number of CFU bacterial counts are shown in Table 1.

Table 1. Descriptive statistics using the number of Colony Forming Units (CFU) for the analyses.

\begin{tabular}{lcccc}
\hline \multicolumn{1}{c}{ Values } & \multicolumn{4}{c}{ Times $(\mathrm{CFU})$} \\
& $\mathrm{T} 1(\mathrm{CFU})$ & $\mathrm{T} 2(\mathrm{CFU})$ & $\mathrm{T} 3(\mathrm{CFU})$ & T4 $(\mathrm{CFU})$ \\
\hline Mean & $2,207,420$ & 12,337 & 2,250 & 1,787 \\
SD & $3,735,644$ & 18,945 & 3,625 & 2,976 \\
Median & 70,000 & 1,800 & 700 & 400 \\
Q1-Q3 & $13,250-3,100,500$ & $880-20,200$ & $400-2,125$ & $129-1,500$ \\
Maximum & $9,500,000$ & 42,000 & 12,000 & 8,000 \\
Minimum & 800 & 400 & 400 & 60 \\
\hline
\end{tabular}

Friedman's test indicated a significant reduction in CFU in all samples collected, considering the four reading times $(\mathrm{p}<0.01)$. The box plot graph (Figure 1) shows a marked decrease in bacterial colonization in the root canals. The Wilcoxon test, comparing paired times, observed significant results between T1-T2 $(\mathrm{p}=0.035), \mathrm{T} 1-\mathrm{T} 3(\mathrm{p}=0.006)$ and $\mathrm{T} 1-\mathrm{T} 4 \quad(\mathrm{p}=0.030)$. The other comparisons, T2-T3 $(\mathrm{p}=0.208) ; \mathrm{T} 2-\mathrm{T} 4$ $(\mathrm{p}=0.291)$; and T3-T4 $(\mathrm{p}=0.673)$, were not significant. 


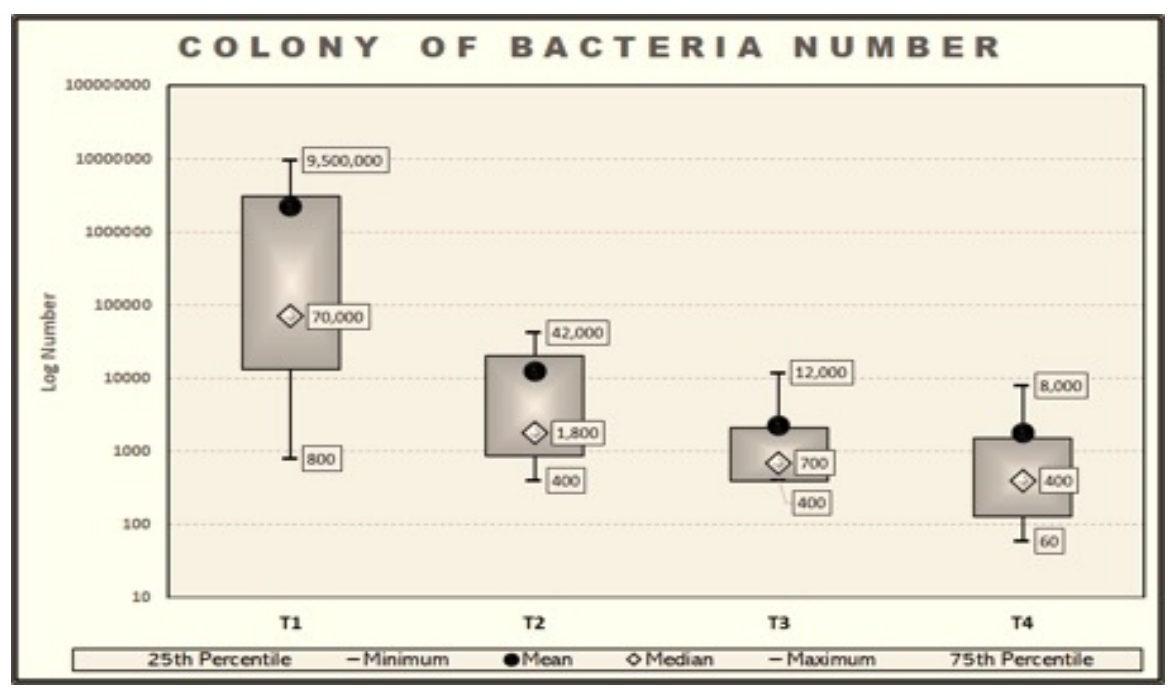

Figure 1. Bacterial colonization in the root canals throughout the clinical stages.

\section{Discussion}

The purpose of using aPDT in this pilot study was to evaluate the bacterial reduction in necrotic canals of primary teeth through adjuvant therapy. For the use of this aPDT therapy and for microbiological analysis, this study followed the same protocol published in the literature $[1,6,8,9]$.

The present study showed a significant reduction in the number of bacteria between times $\mathrm{T} 1-\mathrm{T} 2, \mathrm{~T} 1-$ T3 and T1-T4. This bacterial reduction occurred mainly after the first application of aPDT (99.45\% reduction in bacteria).

No significant reduction in CFU was found using aPDT after the mechanical-chemical preparation of the root canals. Our results are in accordance with a clinical trial conducted recently on primary necrotic teeth [1]. The authors observed that the microbiological results achieved with conventional endodontic treatment combined with aPDT were similar to those achieved only with conventional treatment [1]. However, the results of this research also revealed that after the chemical-mechanical preparation of the canals and the application of aPDT there was still a 20.5\% reduction in CFU. This result was extremely important since studies show that the decrease in bacteria in the root canals is associated with a better prognosis for endodontic treatments, with bacterial persistence being pointed out as the main failure of this therapy $[13,14]$.

Studies evaluating the effectiveness of aPDT in deciduous teeth are still scarce. Most studies are done on permanent teeth [1]. Generally, aPDT therapy is considered a possible alternative to assist in the eradication of bacteria in root canals [16-19].

Considering the rates of bacterial reduction found in the present study, aPDT presented itself as an important aid in the decontamination process, especially in cases where the infection rate is more intense. This result is similar to other studies in primary teeth that used aPDT combined with methylene blue as a photosensitizer $[1,6,9]$. The properties of methylene blue are well established in the literature, with positive charge, low molecular weight and hydrophilicity, which allow the dye to interact with anionic lipopolysaccharide macromolecules and penetrate the external membrane of Gram-negative bacteria [15]. However, different challenges are faced when aPDT therapy is applied to different types of Gram-positive bacteria, Gram-negative bacteria and fungi. 
Regarding the non-bacterial reduction in T2-T3 times, when this data is observed in isolation, it is suggested that the instrumentation phase was not sufficient for the drastic decontamination of the canals. The scientific literature does not consider this statement to be true. On the contrary, it is reported that the root canal system's decontamination occurs mainly during the instrumentation stage [20]. Considering that there was a great decrease in the colony-forming units, the lack of sensitivity of the nonparametric test may be a justification for not having found a significant difference between the times T2 and T3 in the present study. However, a study that compared the effectiveness of aPDT with manual and rotary instrumentation agrees with our findings and stated that instrumentation alone is not sufficient for complete bacterial elimination $[21]$.

The bacterial collection was performed $1 \mathrm{~mm}$ before the end of the root canal. It should be considered that the largest number of bacteria in cases of pulp necrosis is found along the canal, especially in the middle and cervical thirds of the root [22,23]. Thus, it is believed that this factor did not contribute to the lack of statistical significance between times T2 and T3.

Another finding of our study was the bacterial reduction between times T3 (after mechanical chemical preparation) and $\mathrm{T} 4$ (the second application of aPDT after mechanical chemical preparation). Despite the absence of statistical significance, this result reinforces the importance of mechanical instrumentation as a primary step in reducing the intracanal bacterial flora. The lack of statistical significance found after the application of aPDT leads us to a new scientific question: It is known that the approach of this therapy combines light, a low power laser and a photosensitizing agent and, when in contact with microorganisms, it results in the release of singlet oxygen and free radicals. As a result, the amount of oxygen present during aPDT can also interfere with the antimicrobial action [15]. Thus, studies with other protocols are suggested, using, for example, hydrogen peroxide before the application of aPDT.

The present study has the limitation of having a small sample number, so similar clinical studies with a larger number of samples are suggested to confirm the results found in this study.

Despite following the same aPDT application protocol described in other studies [1,6,9], this study advances with the introduction of microbial assessment in a baseline stage. It is not part of the clinical protocol to perform aPDT before the instrumentation of the canals. However, in this clinical study, such an experimental step (T1) was included as a baseline to distinguish the influence of aPDT from the effect of instrumentation on the microbial count. The evaluation of a baseline stage is supported by studies that evaluate the effectiveness of bacterial reduction in the root canal system for different endodontic procedures [13,14]. Without this assessment of step T1, it would not be possible to determine the influence of aPDT alone in reducing the amount of bacteria.

Finally, the need to manage children's behavior and the anatomical and physiological characteristics of primary teeth can make it difficult to disinfect the root canal during chemical-mechanical instrumentation. Thus, the combined use of photosensitizing dye and a low-intensity laser is a viable, low-cost and nontraumatic alternative to complement conventional endodontic therapy in primary teeth.

\section{Conclusion}

Antimicrobial photodynamic therapy can be used as an adjunct in the endodontic treatment of primary teeth, contributing to a significant reduction in the total number of bacteria in primary teeth with necrotic pulp. 


\section{Authors' Contributions}

\begin{tabular}{|c|c|c|}
\hline MLMF & (iD) $0000-0002-5120-1449$ & $\begin{array}{l}\text { Conceptualization, Methodology, Investigation, Formal Analysis, Resources, } \\
\text { Writing - Original Draft Preparation and Writing - Review And Editing. }\end{array}$ \\
\hline CAM & (iD) $0000-0002-0751-5053$ & Writing - Original Draft Preparation. \\
\hline AMCS & (iD) $0000-0002-6864-246 \mathrm{X}$ & Writing - Original Draft Preparation. \\
\hline $\mathrm{CRV}$ & (D) $0000-0001-7893-2762$ & Writing - Original Draft Preparation. \\
\hline FRA & (iD) $0000-0003-2265-7807$ & Writing - Original Draft Preparation. \\
\hline MLM & (iD) $0000-0002-7526-281 \mathrm{X}$ & $\begin{array}{l}\text { Conceptualization, Methodology, Investigation, Formal Analysis, Resources and } \\
\text { Writing - Original Draft Preparation. }\end{array}$ \\
\hline LBS & (iD) $0000-0002-2020-9958$ & $\begin{array}{l}\text { Conceptualization, Methodology, Formal Analysis, Resources and Writing - } \\
\text { Original Draft Preparation. }\end{array}$ \\
\hline $\mathrm{AMF}$ & (iD) $0000-0001-6928-2024$ & $\begin{array}{l}\text { Conceptualization, Methodology, Formal Analysis, Resources and Writing - } \\
\text { Original Draft Preparation. }\end{array}$ \\
\hline
\end{tabular}

\section{Financial Support}

None.

\section{Conflict of Interest}

The authors declare no conflicts of interest.

\section{References}

[1] Okamoto CB, Bussadori SK, Prates RA, da Mota ACC, Horliana ACRT, Fernandes KPS, et al. Photodynamic therapy for endodontic treatment of primary teeth: a randomized controlled clinical trial. Photodiagnosis Photodyn Ther 2020; 11:101732. https://doi.org/10.1016/j.pdpdt.2020.101732

[2] Zorita-García M, Alonso-Ezpeleta LÓ, Cobo M, Del Campo R, Rico-Romano C, Mena-Álvarez J, et al. Photodynamic therapy in endodontic root canal treatment significantly increases bacterial clearance, preventing apical periodontitis. Quintessence Int 2019; 50(10):782-9. https://doi.org/10.3290/j.qi.a43249

[3] Segura-Egea JJ, Gould K, Sen BH, Jonasson P, Cotti E, Mazzoni A, et al. Antibiotics in endodontics: a review. Int Endod J 2017; 50(12):1 169-84. https://doi.org/10.1111/iej.12741

[4] Zargar N, Marashi MA, Ashraf H, Hakopian R, Beigi P. Identification of microorganisms in persistent/secondary endodontic infections with respect to clinical and radiographic findings: bacterial culture and molecular detection. Iran J Microbiol 2019; 11(2):120-8.

[5] Bouillaguet S, Manoil D, Girard M, Louis J, Gaïa N, Leo S, et al. Root microbiota in primary and secondary apical periodontitis. Front Microbiol 2018; 9:2374. https://doi.org/10.3389/fmicb.2018.02374

[6] Pinheiro SL, Schenka AA, Neto AA, de Souza CP, Rodriguez HMH, Ribeiro MC. Photodynamic therapy in endodontic treatment of deciduous teeth. Lasers Med Sci 2009; 24:521-6. https://doi.org/10.1007/s 10103-008-05622

[7] Garcez AS, Roque JÁ, Murata WH, Hamblin MR. A new approach for antimicrobial endodontic PDT. Rev Assoc Paul Cir Dent 2016; 70(2):126-30.

[8] da Mota AC, Gonçalves ML, Bortoletto C, Olivan SR, Salgueiro M, Godoy C, et al. Evaluation of the effectiveness of photodynamic therapy for the endodontic treatment of primary teeth: study protocol for a randomized controlled clinical trial. Trials 2015; 16:551. https://doi.org/10.1186/s 13063-015-1086-2

[9] Okamoto CB, Motta LJ, Prates RA, DaMotta ACC, Gonçalves MLL, Horliana ACRT et al. Antimicrobial photodynamic therapy as a co-adjuvant in endodontic treatment of deciduous teeth: case series. Photochem Photobiol 2018: 94(4):760-4. https://doi.org/10.1111/php.12902

[10] Sarda RA, Shetty RM, Tamrakar A, Shetty SY. Antimicrobial efficacy of photodynamic therapy, diode laser, and sodium hypochlorite and their combinations on endodontic pathogens. Photodiagnosis Photodyn Ther 2019; 28:26572. https://doi.org/10.1016/j.pdpdt.2019.09.009

[11] Plotino G, Grande NM, Mercade M. Photodynamic therapy in endodontics. Int Endod J 2019; 52(6):760-74. https://doi.org/10.1111/iej.13057

[12] de Sant'Anna G. Photodynamic therapy for the endodontic treatment of a traumatic primary tooth in a diabetic pediatric patient. J Dent Res Dent Clin Dent Prospects 2014; 8(1):56-60. https://doi.org/10.5681/joddd.2014.010 
[13] Zandi H, Rodrigues RC, Kristoffersen AK, Enersen M, Mdala I, Ørstavik D et al. Antibacterial effectiveness of 2 root canal irrigants in root-filled teeth with infection: a randomized clinical trial. J Endod 2016; 42(9):1307-13. https://doi.org/10.1016/j.joen.2016.06.006

[14] Rôças IN, Siqueira Jr JF. In vivo antimicrobial effects of endodontic treatment procedures as assessed by molecular microbiologic techniques. J Endod 2011;37(3):304-10. https://doi.org/10.1016/j.joen.2010.11.003

[15] Oliveira BP, Aguiar CM, Câmara AC. Photodynamic therapy in combating the causative microorganisms from endodontic infections. Eur J Dent 2014; 8:424-30. https://doi.org/10.4103/1305-7456.137662

[16] Amaral RR, Cohen S, Ferreira MVL, Soares BM, Côrtes MIS. Antimicrobial photodynamic therapy associated with long term success in endodontic treatment with separated instruments: a case report. Photodiagnosis Photodyn Ther 2019; 26:15-8. http://doi.org/10.1016/j.pdpdt.2019.02.015

[17] da Silva CC, Chaves Júnior SP, Pereira GLD, Fontes KBFDC, Antunes LAA, Póvoa HCC, et al. Antimicrobial photodynamic therapy associated with conventional endodontic treatment: a clinical and molecular microbiological study. Photochem Photobiol 2017; 94(2):351-6. https://doi.org/10.1111/php.12869

[18] de Oliveira BP, Câmara AC, Ferreira GDS, Neto SPS, da Silva PFC, Aguiar CM. Photodynamic therapy: a novel ally for surgical endodontic treatment? case report. J Lasers Med Sci 2018; 9(4):288-90. https://doi.org/10.15171/jlms.2018.51

[19] de Oliveira BP, Aguiar CM, Câmara AC, de Albuquerque MM, Correia AC, Soares MF. The efficacy of photodynamic therapy and sodium hypochlorite in root canal disinfection by a single-file instrumentation technique. Photodiagnosis Photodyn Ther 2015; 12(3):436-43. https://doi.org/10.1016/j.pdpdt.2015.05.004

[20] Souza LC, Brito PR, de Oliveira JC, Alves FR, Moreira EJ, Sampaio-Filho HR, et al. Photodynamic therapy with two different photosensitizers as a supplement to instrumentation/irrigation procedures in promoting intracanal reduction of Enterococcus faecalis. J Endod 2010; 36(2):292-6. https://doi.org/10.1016/j.joen.2009.09.041

[21] Pinheiro SL, Silva JN, Gonçalves RO, Villalpando KT. Manual and rotary instrumentation ability to reduce Enterococcus faecalis associated with photodynamic therapy in deciduous molars. Braz Dent J 2014; 25(6):502-7. https://doi.org/10.1590/0103-6440201302414

[22] Silva LAB, Silva RAB, Nelson-Filho P, Cohence N. Intracanal Medication in Root Canal Desinfection. In: Cohenca N. Desinfection of Root Canal Systems: The Treatment of Apical Periodontitis. New Jersey: Willey-Blackwell; 2014.

[23] American Academy of Peadiatric Dentistry. Guideline on pulp therapy for primary and immature permanente teeth. Pediatr Dent 2016; 38(6):280-8. 